\title{
Reflexões sobre a comissão intra-hospitalar de doação de órgãos e tecidos para transplantes
}

Rafaela Alves Arcanjo ${ }^{1}$, Lilian Candiá de Oliveira ${ }^{2}$, Delma Dias da Silva ${ }^{3}$

\section{Resumo}

Trata-se de estudo de revisão de literatura com o objetivo de caracterizar a legislação vigente com pertinência aos obstáculos encontrados pela Comissão Intra-Hospitalar de Doação de Órgãos e Tecidos para Transplantes. Observou-se que devem ser tomadas medidas de educação contínua entre os profissionais que atuam nessa comissão, bem como conhecer o perfil cultural da população que atende e levar à sociedade informações pertinentes ao processo de doação, visando suscitar entre as famílias essa discussão e, quem sabe assim, reduzir as filas de espera por um transplante no Brasil.

Palavras-chave: Doação de órgãos. Transplantes. Ética.

\section{Resumen}

Reflexiones acerca de la comisión intrahospitalaria de donación de órganos y tejidos para trasplantes

Se trata de un estudio de repaso de la literatura que tiene como objetivo caracterizar la legislación vigente que se refiere a los obstáculos encontrados por la Comisión de Donación Intrahospitalaria de Donación de Órganos y Tejidos para Trasplante. Se observó que se debe adoptar medidas de educación continua entre los profesionales que actúan en este comité, así como conocer el perfil cultural de la población que atiende y llevar a la sociedad informaciones relacionadas con este proceso de donación con el fin de plantear esta discusión entre las familias y, quizá, reducir las listas de espera para un trasplante en Brasil.

Palabras-clave: Donación de órganos. Trasplante. Ética.

\section{Abstract}

Reflections about intra-hospital commission about organs and tissues donation for transplants

This is a literature review with the aim of characterizing the legislation that refers to the obstacles encountered by Intra Hospital Commission of Organs and Tissues Donation for Transplantation. It was observed that should be taken continuing education measures among health professionals in this committee to know the cultural profile of the population which serves this population and lead to relevant information to the donation process in order to raise this discussion between families and perhaps thereby reduce waiting lists for a transplant in Brazil.

Key words: Organ donation. Transplant. Ethics.

1. Especialista rafaelaarcanjo@yahoo.com.br - Hospital São João Batista, Viçosa/MG, Brasil 2. Especialista lylycajf@yahoo.com.br Hospital Universitário de Juiz de Fora; Clínica de Oncologia de Juiz de Fora (CenterQ) 3. Especialista enfermeiraufjf@ig.com.br - Hospital Universitário de Juiz de Fora; Hospital João Penido de Juiz de Fora, Juiz de Fora/MG, Brasil.

Correspondência

Rafaela Alves Arcanjo - Rua Vicente de Paula, 95 Sagrada Família CEP 36570-000. Viçosa/MG, Brasil.

Declaram não haver conflito de interesse. 
No Brasil, os transplantes de órgãos tiveram início na década de 60, mas, segundo o Ministério da Saúde (MS), esse tratamento pouco se difundiu em razão da baixa sobrevida dos pacientes transplantados. No entanto, após 15 anos, a atividade ganhou importância com o desenvolvimento e criação de técnicas cirúrgicas, equipamentos de suporte, métodos de determinação de histocompatibilidade entre doador e receptor e, finalmente, com o advento dos fármacos imunossupressores. Por fim, esses procedimentos difundiram-se entre estabelecimentos hospitalares, aumentando a necessidade de regulamentação para a doação e transplante de órgãos ${ }^{1}$.

Durante quase trinta anos, no período de 1968 a 1990, a atividade de transplante era pouco regulamentada. Existiam regulamentações locais e regionais, desenvolvidas com informalidade no que diz respeito à inscrição de receptores, ordem de transplantes, retirada de órgãos e critérios de distribuição dos órgãos captados ${ }^{2}$. Em 1992, o quadro começa a se alterar com a Lei $8.489^{3}$, que teve vigência até 4 de fevereiro de 1997, sendo substituída pela Lei $9.4344^{4}$, posteriormente alterada em alguns dispositivos no ano de 2001 pela Lei $10.211^{5}$, que se refere à legitimidade de autorização para a retirada de órgãos, inscrição de lista única de espera, além da permissão à pessoa juridicamente capaz de dispor gratuitamente de tecidos, órgãos e partes do próprio corpo vivo.

Em setembro de 2005 foi instituída a regulação dos transplantes no Sistema Único de Saúde
(SUS), por intermédio da Portaria 1.752/GM/MS, que determinava a constituição de Comissão IntraHospitalar de Doação de Órgãos e Tecidos para Transplantes (Cihdott) em todos os hospitais privados, públicos e filantrópicos que disponibilizassem mais de 80 leitos. Tal medida teve o propósito de melhorar a organização do processo de captação de órgãos e viabilizar a ampliação qualitativa e quantitativa no transplante de órgãos ${ }^{6}$. No ano seguinte, com a Portaria 1.262, de 16 de junho de 2006, o Ministério da Saúde aprova o regulamento técnico para estabelecer as atribuições, deveres e indicadores de eficiência e do potencial de doação de órgãos e tecidos relativos às Cihdott ${ }^{7}$.

Com essa legislação, cria-se no ambiente hospitalar uma mudança frente à captação e doação de órgãos: uma comissão capaz de efetivar a proposta de doação, além de promover a descentralização das obrigações institucionais e profissionais dentro do ambiente hospitalar ${ }^{7}$. Em 2009, a Portaria $2.600 \mathrm{GM} / \mathrm{MS}$, de 21 de outubro, aprova o regulamento técnico do Sistema Nacional de Transplantes, regulamentando os serviços das Cihdott nas instituições hospitalares e definindo seus deveres e funções ${ }^{8}$.

Para melhor entendimento do contexto histórico das legislações pertinentes ao tema estabelecido neste estudo, que norteiam o processo de doação e captação de órgãos, enfatizamos as leis, suas datas de criação e implementação, bem como o objetivo de cada uma delas (Quadro 1).

Quadro 1. Principais leis e portarias que enfatizam em seus artigos as comissões intra-hospitalares de doação de órgãos e tecidos para transplantes

\begin{tabular}{|c|c|l|}
\hline \multicolumn{1}{|c|}{ Leis } & Data de criação & \multicolumn{1}{c|}{ Ementa } \\
\hline- & 1968 a 1997 & Regulamentações locais \\
\hline 8.489 & $4 / 11 / 1992$ & Revogada pela Lei 9.434, de $4 / 2 / 1997$ \\
\hline 9.434 & $23 / 3 / 2001$ & $\begin{array}{l}\text { Dispõe sobre a remoção de órgãos, tecidos e partes do corpo } \\
\text { humano para fins de transplante e tratamento e dá outras } \\
\text { providências }\end{array}$ \\
\hline 10.211 & Altera os arts. $2^{\circ}, 4^{\circ}, 8^{\circ}, 9^{\circ}$ e 10 \\
\hline Portarias & Data de criação & Revoga os parágrafos $1^{\circ}, 2^{\circ}, 3^{\circ}, 4^{\circ}$ e $5^{\circ}$ do art. $4^{\circ}$ da Lei 9.434 \\
\hline $1.752 / G M / M S$ & $23 / 9 / 2005$ & $\begin{array}{l}\text { Determina a criação de comissões intra-hospitalares de doação } \\
\text { de órgãos e tecidos para transplantes em todos os hospitais } \\
\text { públicos, privados e filantrópicos com mais de } 80 \text { leitos }\end{array}$ \\
\hline 1.262 & $16 / 6 / 2006$ & $\begin{array}{l}\text { Aprova o regulamento técnico para estabelecer atribuições, } \\
\text { deveres e indicadores de eficiência e do potencial de doação } \\
\text { de órgãos e tecidos relativos às comissões intra-hospitalares }\end{array}$ \\
\hline 2.600 & $21 / 10 / 2009$ & $\begin{array}{l}\text { Aprova o regulamento técnico do Sistema Nacional de } \\
\text { Transplantes }\end{array}$ \\
\hline
\end{tabular}

O objetivo deste estudo de revisão foi levantar a totalidade da legislação pertinente à criação da comissão intra-hospitalar de doação de órgãos e tecidos para transplantes, bem como sua estrutura ética e a efetiva atuação no ambiente hospitalar e extra-hospitalar. 
Funcionamento do sistema de transplante no Brasil

Segundo a Associação Brasileira de Transplantes de Órgãos (Abto), em 2006 houve significativo aumento no número de centros transplantadores cadastrados no Brasil ${ }^{9}$, mas a distribuição geográfica dos mesmos ainda não é feita de maneira igualitária, podendo-se inferir que as diferenças regionais, como o perfil socioeconômico-cultural dos estados brasileiros, possuem impactos decisórios na distribuição desses centros ${ }^{10}$.

Em 1997, após a criação do Sistema Nacional de Transplantes (SNT) e sua real operacionalização em agosto de $1998^{10}$, a estrutura nacional de transplantes foi formada pelas centrais de notificação, distribuição e captação de órgãos em todos os estados brasileiros. Seu funcionamento foi estabelecido por meio do Decreto 2.268, de 30 de junho de $1997^{11}$, que regulamenta a citada Lei 9.434 , de fevereiro daquele ano. Esta lei dispõe sobre a remoção de órgãos, tecidos e partes do corpo humano para transplante e tratamento, o que contribuiu para o desenvolvimento das atividades de captação e transplantes no país ${ }^{10}$. De acordo com a Portaria 1.262, integram o SNT o Ministério da Saúde, secretarias de saúde dos estados e do Distrito Federal ou órgãos equivalentes, secretarias de saúde dos municípios ou equivalentes, estabelecimentos hospitalares autorizados e a rede de serviços auxiliares, necessários à realização de transplantes ${ }^{7}$.

A crescente desproporção do número de pacientes em lista versus o número de transplantes é inquestionável. Dentre os fatores que a determinam estão a não notificação de paciente com diagnóstico de morte encefálica às centrais de notificação, distribuição e captação de órgãos, apesar da obrigatoriedade ${ }^{12}$. A regulamentação dos transplantes, pela Portaria 1.752/GM/MS ${ }^{6}$, pretende envolver de forma mais organizada os hospitais integrantes do SUS no esforço coletivo de captar órgãos, especialmente nas unidades de tratamento intensivo (UTI) cadastradas como de tipo II e III, integrantes dos sistemas hospitalares estaduais de atendimento de urgências e emergências e/ou as que realizem transplantes. Com isto, esperava-se aprimorar o funcionamento das centrais de notificação, captação e distribuição de órgãos, dotando-as de instrumentos que permitissem melhor comunicação com os hospitais integrantes do SUS ${ }^{6,13}$.

Portanto, a Portaria $2.600 \mathrm{GM} / \mathrm{MS}$ define que as centrais de notificação, distribuição e captação de órgãos terão vínculo direto com os profissionais que compõem a comissão intra-hospitalar de doação de órgãos e tecidos para transplantes, visando a melhoria da organização hospitalar referente ao processo de transplantes como um todo. A portaria pretende, ainda, maximizar o envolvimento dos diversos setores que integram o SUS, além dos setores privados de saúde, medida que, se espera, produza melhorias substanciais no serviço, refletindo-se também nos dados estatísticos de transplantes de órgãos.

\section{Cihdott: melhor abordagem de profissionais capacitados}

É determinado que a Cihdott deve ser instituída pela direção de cada hospital, mediante ato formal, e diretamente vinculada à diretoria médica da instituição. A comissão deverá ser composta por, no mínimo, três membros, dentre estes um médico ou enfermeiro, que deverá ter feito o curso de coordenador intra-hospitalar de doação de órgãos e tecidos para transplantes ${ }^{6}$.

O processo de captação inicia-se com a identificação do potencial doador, que pode ser feita por qualquer profissional de saúde. $\mathrm{O}$ diagnóstico de morte encefálica (ME), entretanto, cabe ao médico assistente, em especial ao intensivista, que deverá encaminhá-lo à Cihdott. Contudo, o Capítulo II, art. $3^{\circ}$ da Lei 9.434 dispõe que a retirada post mortem de tecidos ${ }^{4}$ deverá ser precedida de diagnóstico de morte encefálica constatada e registrada por dois médicos, os quais não podem ser participantes das equipes de remoção e transplante. O diagnóstico deve ser estabelecido mediante a utilização de critérios clínicos e tecnológicos definidos pela Resolução 1.346/91 do Conselho Federal de Medicina (CFM) ${ }^{14}$.

É designado à Cihdott, juntamente com a Central de Notificação, Captação e Distribuição de Órgãos (CNCDO), avaliar a capacidade da instituição em detectar potenciais doadores, considerando as características institucionais para que se possa determinar, por meio dos indicadores institucionais, sua competência de atendimento para captação de doadores e realização de transplantes de órgãos. Além disso, é necessário definir os parâmetros que deverão ser adotados no acompanhamento das metas de contratualização, definidas de acordo com a quantidade e qualidade das captações e transplantes de órgãos, determinadas pela Portaria 1.752/ $\mathrm{GM} / \mathrm{MS}^{6}$, e encaminhar ao gestor local os indicadores de desempenho estabelecidos para o hospital, com a adoção de medidas para aperfeiçoar a captação de órgãos e tecidos, estabelecendo metas de atuação com prazo determinado. 
A Cihdott deve promover a integração com todas as unidades que dispõem de recursos diagnósticos necessários para atender os casos de possível doação, além de organizar, na instituição, rotinas e protocolos que possibilitem o processo de doação e captação de órgãos e tecidos ${ }^{10}$. Segundo a Portaria 1.262/GM/MS, cabe à Cihdott manter contato com a CNCDO do estado para organizar o processo de doação e captação de órgãos e tecidos ${ }^{7}$. À CNCDO cabe promover programas de educação/sensibilização continuados e dirigidos à sociedade, além do estabelecimento de critérios de eficiência que possibilitem uma análise de resultados ${ }^{15}$.

O profissional responsável pela atuação na Cihdott deve deter conhecimento prévio sobre o processo de morte, possuir habilidade de comunicação interpessoal, conhecer o processo de doação de órgãos e tecidos, as documentações e legislações específicas e todos os aspectos éticos que envolvem a doação de órgãos e tecidos. É importante que a avaliação profissional seja efetivada e aprimorada após a realização de cada processo na captação de doação de órgãos, tomando como base os pontos positivos e negativos de cada experiência profissional, e que essas experiências sejam discutidas em reuniões organizadas para minimizar as possíveis falhas.

Para melhor e mais profunda avaliação do conhecimento dos profissionais que lidam no dia a dia com o processo de doação frente à Cihdott, faz-se necessário ampliar a proposta de estudo deste trabalho mediante pesquisas de campo, com o intuito de levantar a percepção desses profissionais sobre o tema.

Entretanto, na falta de tais estudos pode-se traçar um quadro geral baseado na obrigatoriedade da formação de coordenador de Cihdott, conforme estabelecido pela Portaria 1.752/GM/MS, que representa apenas um pequeno e primeiro passo na capacitação do profissional para a execução do processo de captação e doação de órgãos. Disto se pode inferir que este processo de formação, isoladamente, é apenas o início da aprendizagem. Sugere-se, por exemplo, que cada instituição deva conhecer o perfil cultural da população a qual atende, para transmitirIhe as informações pertinentes ao processo de doação, provocando essa discussão entre as famílias.

\section{Desafios na implantação das comissões intra- hospitalares}

Para a implantação das Cihdott, muitas questões devem ser levantadas, entre elas a ética, pri- mordial à efetivação do trabalho desta comissão. Assim, suscitaremos alguns dilemas para tratarmos de um assunto que envolve tantos questionamentos e dúvidas.

Segundo Souza ${ }^{16}$, os sentidos atribuídos à palavra "ética" vêm se modificando ao longo dos séculos, incorporando novas acepções e atributos, se aperfeiçoando e diversificando de acordo com o contexto na qual está inserida. Esta alteração do sentido das palavras e termos ocorre em todas as circunstâncias nas quais as ideias se modificam de acordo com um contexto cultural específico e são transmitidas a outras sociedades, que incorporam seus próprios valores e visões de mundo ao sentido original. É o que ocorre com a ideia de "ética" no mundo contemporâneo, que vem se transformando em decorrência tanto das aceleradas trocas culturais promovidas pelos meios de comunicação quanto como resultado do uso de novas tecnologias e processos na área da saúde.

Exemplifica a afirmação acima a definição de morte cerebral ou encefálica, criada e utilizada desde a década de 60 nos Estados Unidos e parte da Europa, para facilitar a doação de órgãos e justificar ventiladores mecânicos ${ }^{17}$. Entretanto, hoje é possível sustentar uma pessoa com diagnóstico de morte cerebral por algumas horas e mesmo por períodos mais longos. Mediante os avanços tecnológicos, pode-se manter o coração de pessoas com morte cerebral batendo "naturalmente". Algumas vezes, um coração pode ser reanimado, ou máquinas podem fazer esse papel. Nestes casos, pessoas em tais situações eram anteriormente chamadas por alguns médicos de cadáveres sem batimentos, epíteto que suscita e reflete os muitos questionamentos éticos relacionados ao processo de doação de órgãos e que traz consigo dilemas e conceitos difundidos ao longo dos anos ${ }^{18}$.

O processo de doação de órgãos, por envolver questões de reciprocidade, terminalidade da vida, autonomia, entre outros valores, bem como virtudes morais, está inserido num contexto muito subjetivo e amplo ${ }^{19}$. Durante o decorrer do processo de morte, a abordagem familiar sobre doação de órgãos, realizada pelo profissional de saúde, deverá ser feita de forma clara e muito bem fundamentada, pois é nesse momento que se define se haverá recusa ou não da família perante a solicitação de doação. Sendo assim, surgem algumas questões: está o profissional realmente capacitado para esclarecer essas pessoas, auxiliando-as a desconstruir seus preconceitos e aclarar suas ideias, facilitando-as a expressar seus desejos? O seu comportamento diante da 
morte condiz com a especificidade do processo? Em nosso entendimento, o profissional de saúde que lida com esses questionamentos deverá estar muito bem preparado para o trato com todos os enlaces éticos envolvidos nesse momento, além de conhecer as leis que o envolvem.

Segundo Vargas ${ }^{18}$, o conceito de morte, apoiado na definição de morte cerebral, proporciona à medicina o direcionamento para distinguir os pacientes para com os quais se tem obrigações diferenciadas. A definição conceitual da morte cerebral pode possibilitar que os órgãos dos indivíduos com esse tipo de laudo sejam utilizados para ajudar pessoas ainda vivas ${ }^{20}$. Tal discussão permite assinalar, questionar e problematizar algumas polaridades, como as relações entre a mente e o corpo; a morte cerebral e a morte orgânica; o reversível e o irreversível; os pacientes vivos e os corpos mortos; o receptor vivo e o doador cadáver ${ }^{18}$; a avaliação clínica-tecnológica da morte; as decisões médicas e as opiniões e valores; o especialista científico e os outros especialistas. Essas dicotomias nos colocam em situações que transcendem nossas experiências e nos envolvem bem mais no contexto de todo o processo, inserindo-nos em situações reais, com dor, tristeza e a possibilidade de estar dando a outro uma nova tentativa para a vida ${ }^{18}$.

A distinção entre as dualidades de vida e morte e entre ser vivo ou ser cadáver, segundo Vargas ${ }^{18}$, está hoje condicionada a padrões mais ou menos consensuados e, portanto, sob o domínio de uma comunidade de profissionais. Isto não quer dizer que comunicações não se estabeleçam entre diferentes círculos e comunidades e que a cultura esteja excluída destes ou das comunicações possíveis entre eles, pois somente por intermédio das comunicações se pode garantir a transparência e confiabilidade do processo ${ }^{21}$.

Uma das características do mundo contemporâneo é o seu enfoque fortemente comportamental, demonstrado por meio de ações de saúde que visam a mudança de hábitos e estilos de vida dos indivíduos, enfatizando o ambiente familiar e o contexto cultural em que vivem. Nesta ótica, podemos salientar que o processo de doação de órgãos tende a ser propiciado pelo processo educativo, ligado a fatores familiares e controlado pelos próprios indivíduos. As campanhas educativas, em geral, focalizam as discussões familiares sobre o tema ou deveriam focalizar, a fim de estimular e proporcionar maiores discussões entre as famílias e esclarecimentos frente ao processo de decisão ${ }^{22}$.
A Cihdott e a educação permanente nos ambientes intra e extra-hospitalares

O funcionamento e existência de comissões intra-hospitalares de transplantes tem permitido melhor organização do processo de captação de órgãos e melhor identificação dos potenciais doadores, com abordagem mais adequada dos familiares e maior articulação do hospital com a respectiva central de notificação, captação e distribuição de órgãos, o que, por fim, viabilizaria a ampliação qualitativa e quantitativa na captação ${ }^{22}$.

Os membros da Cihdott, conforme a Portaria 1.752/GM/MS, devem responsabilizar-se pela educação permanente dos funcionários da instituição sobre os aspectos de doação e transplantes de órgãos e tecidos, sendo uma de suas atribuições a de organizar mecanismos para que seja possível responsabilizar-se pela educação continuada dos funcionários da instituição, familiares e comunidade sobre aspectos de doação e transplante de órgãos e teci$\operatorname{dos}^{23}$. Entendemos que esta é uma proposta de ação estratégica que visa contribuir para a transformação e qualificação das práticas de saúde, com a possível organização das ações dos serviços de saúde ${ }^{24}$.

Os membros da Cihdott devem responsabilizar-se pela educação permanente dos funcionários da instituição. Entretanto, há pouca divulgação do tema, observando-se que inexiste uma política de educação permanente para esses profissionais, quanto ao processo de doação-transplante e todos os desdobramentos decorrentes da falta de conhecimento sobre esse processo ${ }^{22}$. Para muitos educadores, a educação permanente em saúde representa um desdobramento da educação popular de jovens e adultos, perpetuando-se pelos princípios e diretrizes, desde educação e conscientização, bem como educação como prática da liberdade - e também na educação e na mudança ${ }^{24}$.

A educação permanente em saúde configura um desdobramento do Movimento Institucionalista em Educação, que propôs alterar a noção de recursos humanos, que advém da Administração e da Psicologia Organizacional, para a noção de produção de coletivos, com a proposta de criação de dispositivos para que todos possam se reunir e discutir, percebendo que a educação se comporta necessariamente com a reformulação da estrutura e do processo produtivo e nas formas singulares de cada tempo e lugar ${ }^{24,25}$.

A saúde enfrenta problemas como a baixa disponibilidade de profissionais, com a distribuição 
irregular acarretando grande concentração em centros urbanos e regiões mais desenvolvidas, aumento das especializações na saúde e suas consequências sobre os custos econômicos e dependência de tecnologias mais sofisticadas e o constante incremento da formação hospitalar centrada nos aspectos tecnológicos do cuidado em saúde, que demandam transformações na formação de trabalhadores ${ }^{24}$. Segundo Lourau ${ }^{23}$, mesmo que tenhamos todas as especializações e trabalhos com equipes multiprofissionais, estaremos condicionados à melhor e maior resolubilidade dos problemas de saúde das populações locais ou referidas, entretanto estaremos sempre desatualizados, nunca iremos dominar tudo o que se requer em situações complexas para as quais é necessário assegurar amplamente o direito à saúde.

Ao analisar a afirmação acima, concluímos que não serão apenas as especialidades e os incrementos científicos que nos ensinarão a alcançar o verdadeiro conhecimento sobre a comunicação quando envolvidos com o processo de saúde, doença e morte ${ }^{25}$. A opinião da comunidade favorável à doação de órgãos é essencial para solucionar esse problema. Atualmente, a recusa dos familiares é o principal fator limitante dos programas de transplantes de órgãos em vários países ${ }^{24,25}$.

De acordo com Traiber ${ }^{26}$, a maior parte da população recebe informações sobre transplante de órgãos e doação por intermédio dos meios de comunicação de massa - televisão, rádio, jornais, revistas. Um número menor é influenciado por familiares, amigos, profissionais de saúde e campanhas que falam sobre doação de órgãos. Mais importante que o veículo pelo qual a informação é fornecida será a qualidade desta informação. $O$ cidadão bem informado é capaz de promover discussão com familiares e amigos, o que pode configurar-se mecanismo de promoção de doação de órgãos ${ }^{24,26}$.

A Cihdott tem que incentivar as famílias a discutir sobre doação ou acreditar que o paciente poderia desejar ser doador mesmo que não tenha discutido o assunto. Acredita-se que as campanhas que incentivem pessoas a debaterem com seus familiares o assunto doação de órgãos e transplantes sejam fundamentais nos momentos de decisão ${ }^{25}$. Quando a família conhece os desejos do potencial doador, pode mais facilmente deferir sua opinião e as discussões sobre doação de órgãos podem ser realizadas não somente no âmbito familiar como também em escolas e ambientes de trabalho. Cabe às autoridades e aos conhecedores do assunto problematizar e levar tal tema para discussão. É fundamental que sejamos capazes de dialogar com as práticas e concepções vigentes, na realidade do trabalho de cada equipe, e de construir novos pactos de convivência e práticas com o intuito de aproximar os serviços de saúde dos conceitos da atenção humanizada e integral com a qualidade e equidade dos demais marcos dos processos de reforma do sistema brasileiro de saúde ${ }^{24}$.

Destaca-se que o que deve ser realmente central à educação em saúde é a adaptação à realidade mutável das ações e dos serviços de saúde; é a transformação das políticas de formação de perfis profissionais e de serviços, com a introdução de mecanismos, espaços e temas que geram autoanálise, autogestão, mudança institucional, enfim, desdobramentos e rupturas com fórmulas e modelos com experimentação afetada pela realidade ${ }^{24}$.

\section{Considerações finais}

Para melhor e mais profunda avaliação do conhecimento dos profissionais que no dia a dia lidam com o processo de doação frente à Cihdott, faz-se necessário ampliar os estudos deste trabalho mediante pesquisas de campo, com o intuito de levantar a percepção dos profissionais sobre o tema.

Sendo assim, cabe a cada um de nós trabaIhar unindo forças para que com nossas famílias, parentes e amigos possamos discutir sobre doação de órgãos e tecidos para transplantes, com vistas a reafirmarmos nossos desejos, medos e dúvidas ante o processo, o que provavelmente nos tornaria menos vulneráveis. Essas discussões internas representam importante estímulo à participação por um interesse digno e coletivo. Cabe a todos nós promover e estimular o desenvolvimento das atividades relacionadas com transplantes de órgãos e tecidos no Brasil.

\section{Referências}

1. Knobel E, Laselva CR, Moura Junior DF. Terapia intensiva: enfermagem. São Paulo: Atheneu; 2009.

2. Brasil. Ministério da Saúde. Secretaria de Assistência a Saúde. Relatório de gestão 1998/2001 da Secretaria de Assistência a Saúde. $2^{\text {a }}$ ed.rev. Brasília: Ministério da Saúde; 2002. p. 220. 
3. Brasil. Lei $n^{\circ} 8.489$, de 18 de novembro de 1992. Dispõe sobre a retirada e transplante de tecidos, órgãos e partes do corpo humano. Diário Oficial da União. 20 nov. 1992;seção 1:16065.

4. Brasil. Lei n' 9.434 , de 4 de fevereiro de 1997. Dispõe sobre a remoção de órgãos, tecidos e partes do corpo humano para fins de transplante e tratamento e dá outras providências. [internet]. [acesso 26 out. 2011]. Disponível: http://www.planalto.gov.br/ccivil_03/leis/19434.htm

5. Brasil. Lei $n^{\circ} 10.211$, de 23 de março de 2001. Altera dispositivos da Lei $n^{\circ} 9.434$, de 4 de fevereiro de 1997, que dispõe sobre a remoção de órgãos, tecidos e partes do corpo humano para fins de transplante e tratamento. [internet]. [acesso $12 \mathrm{dez}$. 2011]. Disponível: http://www.planalto.gov. br/ccivil_03/leis/LEIS_2001/L10211.htm

6. Brasil. Ministério da Saúde. Portaria $n^{\circ} 1.752$, de 23 de setembro de 2005. Aprova o regulamento técnico para estabelecer as atribuições, deveres e indicadores de eficiência e do potencial de doação de órgãos e tecidos relativos às Comissões Intra-hospitalares de Doação de Órgãos e Tecidos para Transplante (CIHDOTT). Diário Oficial da União. 27 set. 2005;seção 1:54.

7. Brasil. Ministério da Saúde. Portaria $n^{\circ}$ 1.262, de 16 de junho de 2006. Aprova o Regulamento Técnico para estabelecer as atribuições, deveres e indicadores de eficiência e do potencial de doação de órgãos e tecidos relativos às Comissões Intra-hospitalares de Doação de Órgãos e Tecidos para Transplante (CIHDOTT). Diário Oficial da União. 19 jun. 2006;seção 1:41-4.

8. Brasil. Ministério da Saúde. Portaria $n^{\circ} 2.600$, de 21 de outubro de 2009. Aprova o Regulamento Técnico do Sistema Nacional de Transplantes. Diário Oficial da União. 30 out. 2009;seção 1:77118.

9. Associação Brasileira de Transplantes de Órgãos. ABTO; 2011[internet] [acesso 25 out. 2012]. Disponível: www.abto.org.br/abtov03/Upload/file/ABTO_News/2012/1.pdf

10. Roza BA. Efeitos do processo de doação de órgãos e tecidos em familiares: intencionalidade de uma doação [tese]. São Paulo: Escola Paulista de Medicina; 2005. 146 p.

11. Brasil. Decreto $n^{\circ} 2.268$, de 30 de junho de 1997. Regulamenta a Lei $n^{\circ} 9.434$, de 4 de fevereiro de 1997, que dispõe sobre a remoção de órgãos, tecidos e partes do corpo humano para fins de transplante e tratamento, e dá outras providências. Diário Oficial da União. $1^{\circ}$ jul. 1997; seção 1:13739.

12. Schelemberg AM. Análise da notificação de morte encefálica na unidade de terapia intensiva do hospital Governador Celso Ramos, Florianópolis [monografia]. Florianópolis: Universidade Federal de Santa Catarina; 2006.

13. Ehrle RN, Shafer TJ, Nelson KR. Referral, request, and consent for organ donation: best practice-a blueprint for success. Crit Care Nurse. 1999;19(2):21-30.

14. Conselho Federal de Medicina. Resolução n 1.480, de 8 de agosto de 1997. A morte encefálica será caracterizada através da realização de exames clínicos e complementares durante intervalos de tempos variáveis, próprios para determinadas faixa etárias. Revoga-se a resolução CFM $n^{\circ}$ 1.346/91. Diário Oficial da União. 21 ago. 1997;(160) seção 1:18227-8.

15. Barbosa PR, Carvalho Al, Ribeiro JM. Modelos de atenção à saúde: conceitos básicos, aspectos históricos e desafios para práticas inovadoras. [internet]. 24 jul. 2001 [acesso fev. 2012].

16. Souza RT. Fontes do humanismo latino: a condição humana no pensamento filosófico moderno e contemporâneo. Porto Alegre: Edipucrs; 2004.

17. Lock M. Deat in technological time: locating the end of meaningful life. Med Anthropol Q. 1996;10(4):575-600.

18. Vargas MAO, Ramos FRS. A morte cerebral como o presente para a vida: explorando práticas culturais contemporâneas. Texto \& Contexto Enferm. 2006;15(1):137-45.

19. Verdi M, Caponi S. Reflexões sobre a promoção da saúde numa perspectiva bioética. Texto \& Contexto Enferm. 2005;14(1):82-8.

20. Pereira WA, Fernandes RC, Soler WV. I Reunião de diretrizes para captação e retirada de múltiplos órgãos e tecidos da Associação Brasileira de Transplante de Órgãos. São Paulo: Associação Brasileira de Transplante de Órgãos; 2003.

21. Ceccim BR. Educação permanente em saúde: descentralização e disseminação de capacidade pedagógica na saúde. Ciênc Saúde Colet. 2005;10(4):975-86.

22. Freire P. Educação como prática da liberdade. $19^{a}$ ed. Rio de Janeiro: Paz e Terra; 1989.

23. Lourau R. A análise institucional. Petrópolis: Vozes; 1975.

24. Conesa C, Rios A, Ramirez P, Canteras M, Rodríguez MM, Parrilla P. Influence of different sources of information on attitude toward organ donation: a factor analysis. Transplant Proc. 2004;36(5):1.245-8.

25. Smirnoff LA, Gordon N, Hewlett J, Arnold RM. Factors influencing families consent for donation of solid organs for transplantation. Jama. 2001;286(1):71-7.

26. Traiber C, Lopes MHI. Educação para doação de órgãos. Sci Med. 2006;16(4):178-182.

Participação das autoras

Rafaela, Delma e Lilian realizaram a pesquisa bibliográfica, desenvolveram as ideias, definiram o tema e elaboraram o artigo. Rafaela foi responsável pela revisão do artigo para submissão e aprovação com a colaboração das demais autoras.

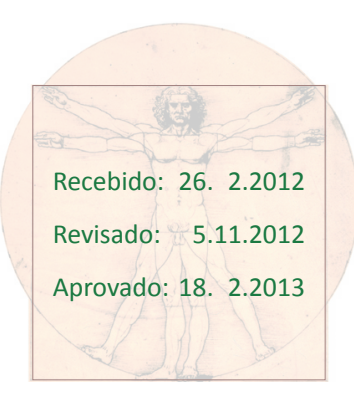

